\title{
A Karyotype Comparison of Nine Species of Aneuploid Zamia by Using the Conventional Orcein Staining and the Fluorochrome CMA-DAPI Differential Staining Methods
}

\author{
Norikazu Tagashira and Katsuhiko Kondo* \\ Laboratory of Plant Chromosome and Gene Stock, Faculty of Science, \\ Hiroshima University, Higashi-Hiroshima City 739-8526, Japan
}

Accepted September 1, 1999

\begin{abstract}
Summary Zamia angustifolia, Z. integrifolia, Z. pumila and Z. pygmaea had the common chromosome number of $2 n=16$ and the common karyotype which consisted of 12 median-, 2 submedianand 2 subterminal-centromeric chromosomes. The 4 species showed commonly the CMA-positive band in the centromeric region of 2 median-, 2 submedian- and 2 subterminal-centromeric chromosomes. In contrast, Z. furfuracea, Z. loddigesii, Z. skinneri and Z. vazquezii had commonly the chromosome number of $2 \mathrm{n}=18$ and 10 median- and 2 submedian-centromeric chromosomes in karyotype but exhibited 6 different chromosomes from each other. Zamia furfuracea and Z. loddigesii displayed the CMA-positive band in the centromeric region of 8 median- and 6 acro-centromeric chromosomes. Zamia skinneri performed the CMA-positive band in the centromeric region of 4 acro- and 2 terminal-centromeric chromosomes, while $Z$. vazquezii performed the CMA-positive band in the centromeric region of 4 median- and 6 terminal-centromeric chromosomes. Zamia muricata had the chromosome number of $2 n=23$ differed from that of the previous count, the karyotype which consisted of 7 median- and 16 acro-centromeric chromosomes and the CMA-positive band in the centromeric region of 4 median- and 16 acro-centromeric chromosomes. Then, the 9 species of Zamia studied exhibited unclear DAPI-positive bands near the centromeric region of most of their chromosomes. By comparison, the closely related Ceratozamia mexicana had the chromosome number of $2 n=16$ and the CMA-positive band at the terminal region of 6 chromosomes.
\end{abstract}

Key words Aneuploid, CMA-DAPI differential staining, Orcein karyotype analysis, Zamia.

Zamia is taxonomically placed in the Cycadales, the Zamineae, the Zamiaceae, Zamioideae (Stevenson 1990, Jones 1993), and is primarily distributed from Central to South America (Jones 1993). Classification of Zamia has been seen in many papers and has described 26 (e.g., Schuster 1932) to 60 species (Jones 1993, Norstog and Nicholls 1997). Zamia might be phylogenetically closely related with Ceratozamia, Chigua and Microcycas all of which are distributed in North and South America (Stevenson 1990, Jones 1993).

Zamia has been well studied in diversity of chromosome numbers from $2 n=16$ to 28 due to interspecific (Marchant 1968, Vovides 1983, Moretti 1990a, b, Moretti et al. 1991, Caputo et al. 1996) and intraspecific aneuploids (Norstog 1980, Moretti and Sabato 1984, Moretti et al. 1991, Vovides and Olivares 1996). This aneuploid series might be promoted by the centric fusion (Marchant 1968, Norstog 1980) or centric fission (Moretti and Sabato 1984, Moretti 1990a, b, Moretti et al. 1991).

Chromosome marking by various banding methods has been applied to many plant species to isolate certain chromosomes which characterized specific taxonomic-groups (e.g., Moretti 198182, Tanaka and Hizume 1980). Fluorescence banding techniques by chromomycin $\mathrm{A}_{3}(\mathrm{CMA})$ and

\footnotetext{
* Corresponding author: E-mail: kkondo@ipc.hiroshima-u.ac.jp
} 
4',6-diaminido-2-phenyliodole (DAPI) have been applied to chromosomes of several cycads such as Ceratozamia (Kokubugata and Kondo 1998), Cycas (Hizume et al. 1992, Kokubugata and Kondo 1996) and Microcycas (Kokubugata and Kondo 1998). Kokubugata and Kondo (1998) demonstrated and stated for the first time that the CMA and DAPI staining methods promised to distinguished certain intergeneric relationships among the cycad genera.

The present study describes chromosome variation and differentiation in 9 species of the aneuploid Zamia detected by the conventional aceto-orcein staining and fluorescence CMA-DAPI differential staining methods.

\section{Materials and methods}

Nine species of Zamia and Ceratozamia mexicana Brongn. studied are listed in Table 1. Classification of Zamia and Ceratozamia followed Jones (1993). The material plants used were male excepting Z. angustifolia Jacq. used was female (Table 1).

Meristematic tissues were isolated from young leaflets by the method of Kokubugata and Kondo (1994): Young leaflets were chopped into small pieces ca. $1.5 \mathrm{~mm}$ across and were treated with $0.002 \mathrm{M} 8$-hydroxyquinoline solution at $4^{\circ} \mathrm{C}$ for $13 \mathrm{~h}$ before they were fixed in $1: 3$ acetic ethanol at $4{ }^{\circ} \mathrm{C}$ overnight. They were washed and stored in $70 \%$ ethanol. The materials were rinsed in distilled water and in $45 \%$ acetic acid at room temperature for $10 \mathrm{~min}$ each. They were macerated in $45 \%$ acetic acid at $60^{\circ} \mathrm{C}$ for $4 \mathrm{~min}$. The preparations were placed on glass slides, were removed trichomes on their epidermis and were chopped into minute pieces about $0.5 \mathrm{~mm}$ across. The preparations were stained in $2 \%$ aceto-orcein in humid chamber at room temperature for $4 \mathrm{~h}$. Then, they were squashed on glass slides for chromosome spreading. Chromosome identification followed Levan et al. (1964): Median-centromeric chromosome ( $=\mathrm{m}$-chromosome; arm ratio=long arm/short arm=1.0-1.7), submedian-centromeric chromosome (=sm-chromosome; arm ratio $=1.8-3.0)$, subterminal-centromeric chromosome (=st-chromosome; arm ratio $=3.1-5.0)$, and terminal-centromeric chromosome ( $=\mathrm{t}$ - and T-chromosomes; arm ratio $=5.1-\infty)$. "t-chromosome" means acrocentric chromosome, and "T-chromosome" means telocentric chromosome. Additionally, microphotographs were made on Minicopy HR-II film (Fuji).

Meristematic tissues used for CMA-DAPI staining were prepared as follows: Young leaflets treated with $0.002 \mathrm{M} 8$-hydroxyquinoline and fixed in $45 \%$ acetic acid were chopped into minute pieces. They were macerated in the enzyme mixture of 3\% cellulase Onozuka R-10 (Yakult) and $0.25 \%$ Pectolyase Y-23 (Seishin) in distilled water $(\mathrm{w} / \mathrm{v})$ at $37^{\circ} \mathrm{C}$ for $20 \mathrm{~min}$. They were washed in distilled water for $10 \mathrm{~min}$ and were squashed in $45 \%$ acetic acid on glass slides. The slides were removed coverslip by the dry-ice method and were air-dried.

The fluorescent CMA and DAPI differential staining methods followed Kokubugata and Kondo (1996): The slides were washed in Macllvain buffer at $\mathrm{pH} 7.0$ for $30 \mathrm{~min}$ and were dropped $50 \mu 1$ of $0.1 \mathrm{~g} / \mathrm{ml}$ Distamysin A (Sigma) dissolved in MacIlvain buffer at $\mathrm{pH} 7.0$ for $10 \mathrm{~min}$. Then, the slides were washed in MacIlvain buffer contained $5 \mathrm{mM} \mathrm{MgSO}_{4}$ at $\mathrm{pH} 7.0$ for $10 \mathrm{~min}$, and then, were dropped $50 \mu 1$ of $0.1 \mathrm{mg} / \mathrm{ml} \mathrm{CMA} \mathrm{(Sigma)} \mathrm{dissolved} \mathrm{in} \mathrm{Macllvain} \mathrm{buffer} \mathrm{contained} 5 \mathrm{mM}$ $\mathrm{MgSO}_{4}$ at $\mathrm{pH} 7.0$ for $10 \mathrm{~min}$. They were washed in MacIlvain buffer contained $5 \mathrm{mM} \mathrm{MgSO}_{4}$ at $\mathrm{pH}$ 7.0 for $10 \mathrm{~min}$ and then, were stained in $2 \mu \mathrm{g} / \mathrm{ml}$ DAPI (Sigma) dissolved in Macllivain buffer at $\mathrm{pH}$ 7.0 at room temperate for $10 \mathrm{~min}$. Then, they were washed in MacIlvain buffer at $\mathrm{pH} 7.0$ for $10 \mathrm{~min}$ and were mounted with coverslips using a drop of $50 \%$ glycerol diluted with distilled water. The slides were observed in an epifluorecence microscope with blue-violet filter (BV-2A; Nikon). Microphotographs were made on T-MAX 400 film (Kodak).

After CMA-banding observation the slides were destained in $45 \%$ acetic acid at room temperature for $30 \mathrm{~min}$. They were air-dried and used for DAPI fluorescence staining as follows: The slides were washed in MacIlvain buffer at $\mathrm{pH} 7.0$ at room temperature for $30 \mathrm{~min}$ and they were 


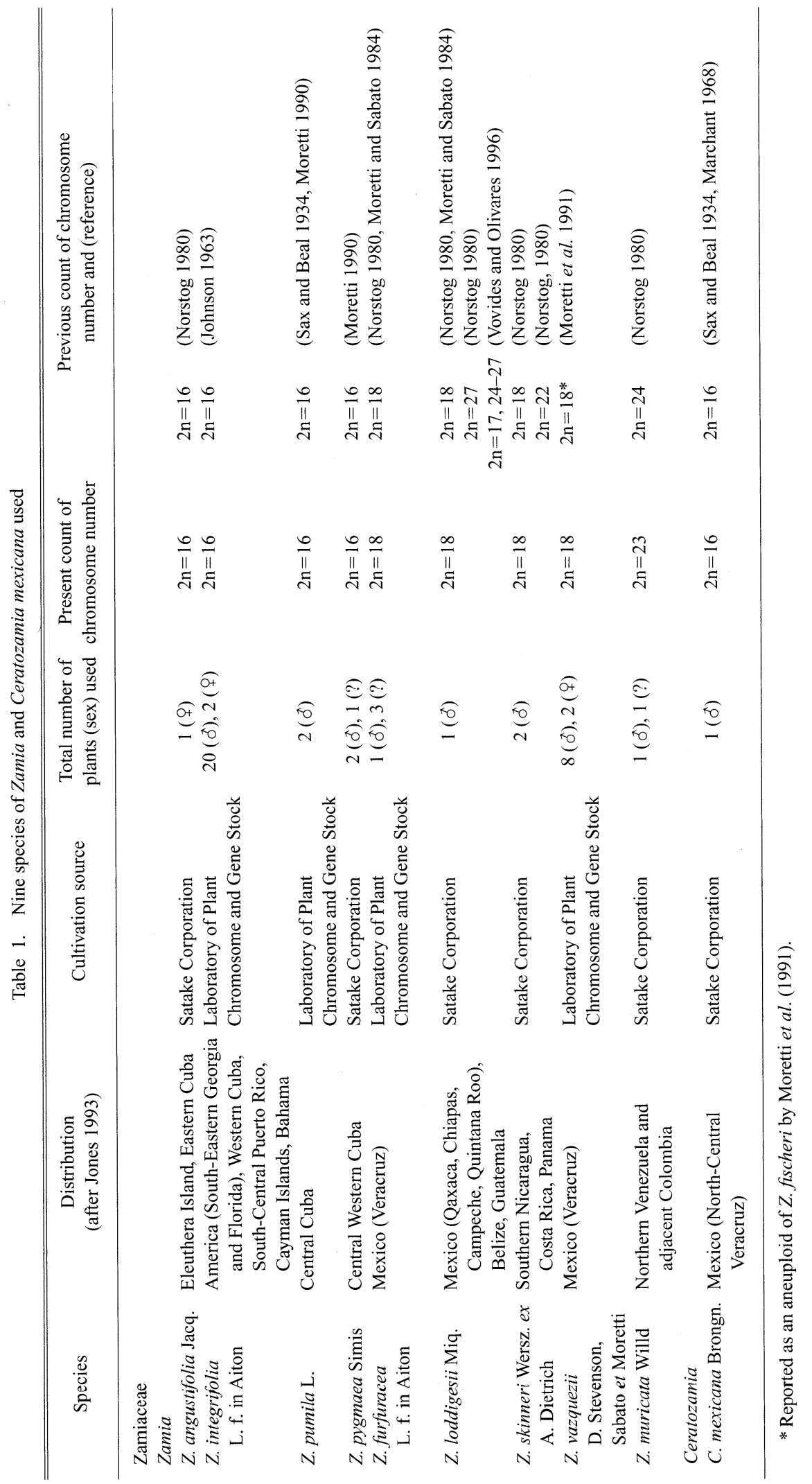


dropped $50 \mu 1$ of $0.1 \mathrm{mg} / \mathrm{ml}$ Actinomysin D (Sigma) dissolved in MacIlvain buffer at $\mathrm{pH} 7.0$ at room temperature. They were washed in MacIlvain buffer at $\mathrm{pH} 7.0$ at room temperature for $10 \mathrm{~min}$, and were stained in $10 \mathrm{mg} / \mathrm{ml}$ DAPI dissolved in MacIlvain buffer at $\mathrm{pH} 7.0$ at room temperature for $30 \mathrm{~min}$. The slides were washed in MacIlvain buffer at $\mathrm{pH} 7.0$ at room temperature for $10 \mathrm{~min}$ and were mounted with coverslips using a drop of $50 \%$ glycerol. The slides were observed on an epifluorescence microscope using UV filter (UV-2A; Nikon). Microphotographs were made on T-MAX 400 film (Kodak).

\section{Results and discussion}

Zimia angustifolia Jacq., Z. integrifolia L.f., Z. pumila L. and Z. pygmaea Simis had commonly the chromosome number of $2 \mathrm{n}=16$ (Fig. 1A-D) and the karyotype consisted of 12 median- (mchromosomes; 1 st to 12th chromosomes), 2 submedian- (sm-chromosome; 13th and 14th chromosomes) and 2 subterminal-centromeric chromosomes (st-chromosomes; 15th and 16th chromosomes). The chromosome numbers of the 4 species were quite the same as those in the previous reports (Table 1). However, their karyotypes were different from those in the previous reports due to different classification of chromosome by centromeric positions; 4 submedian-centromeric chromosomes by Sax and Beal (1934) and Norstog (1980) instead of the present 2 sm- and 2 st-chromosomes. The 2 submedian-centromeric and 2 acro-centromeric chromosomes of the species have already been reported by Moretti (1990b). The secondary constriction was found only on the 1st chromosome or the first median-centromeric chrmosome in Z. pumila in the present study (Fig. 1C), although it was found on 2 median-centromeric chromosomes by Moretti (1990b).

Zamia furfuracea L.f., Z. loddigesii Miq., Z. skinneri Wersz. ex A. Dietrich and Z. vazquezii D. Stevenson, Sabato et Moretti had commonly the chromosome number of $2 \mathrm{n}=18$ (Fig. 1E-H) and $10 \mathrm{~m}$ - (1st to 10th chromosomes) and 2 sm-chromosomes (11th and 12th chromosomes) and uncommonly 6 chromosomes (13th to 18 th chromosomes) which were different in karyomorphology from each other and specified respective species: For instance, the 6 chromosomes of $Z$. furfuracea and $Z$. loddigesii were t-chromosomes and were characterized by their heterochromatic short arm. The 6 chromosomes of $Z$. skinneri consisted of 4 t-chromosomes and 2 T-chromosomes which were characterized by their quite small short arm. The 6 chromosomes of $Z$. vazquezii were T-chromosomes. Even on same slide of each of the 4 species, sizes of the heterochromatic short arms of the tchromosomes varied among the nucleus plates studied. These heterochromatic short arms had been observed on t-chromosome by Marchant (1968) and Moretti (1990b). Then, these arms had not been well-studied and concerned for karyotype analysis. The 6 variable chromosomes of each of the 4 species were carefully concluded here to consist of 2 A-chromosomes referred to st-chromosomes and 4 T-chromosomes referred to t-chromosomes.

Zamia muricata Willd had the chromosome number of $2 n=23$ and the karyotype consisted of $7 \mathrm{~m}$-chromosomes (1st to 7 th chromosomes) and 16 t-chromosomes (8th to 23rd chromosomes) (Fig. 1I). Sizes of the short arm of the t-chromosomes in the species varied among the nucleus plates studied as well as those in the 4 species with $2 \mathrm{n}=18$ (Fig. $1 \mathrm{E}-\mathrm{H})$.

Ceratozamia mexicana had the chromosome number of $2 n=16$ and the karyotype consisted of 12 m-chromosomes (1st to 12th chromosomes), 2 st-chromosomes (13th and 14th chromosomes) and 2 T-chromosomes (15th and 16th chromosomes) (Fig. 1J). Ceratozamia mexicana had small satellites on the terminal region of the short arm of the 11th and 12th chromosomes and of the long arm of the 13th and 14th chromosomes. These satellites were not observed in the Zamia species studied.

Speciation of the 9 species of the aneuploid Zamia studied might be promoted by the phenomenon of the Robertsonian change (Robertson 1916), since total 30 chromosome-arms were presented without counting the short arms of the st-, t- and T-chromosomes (Fig. 1). 


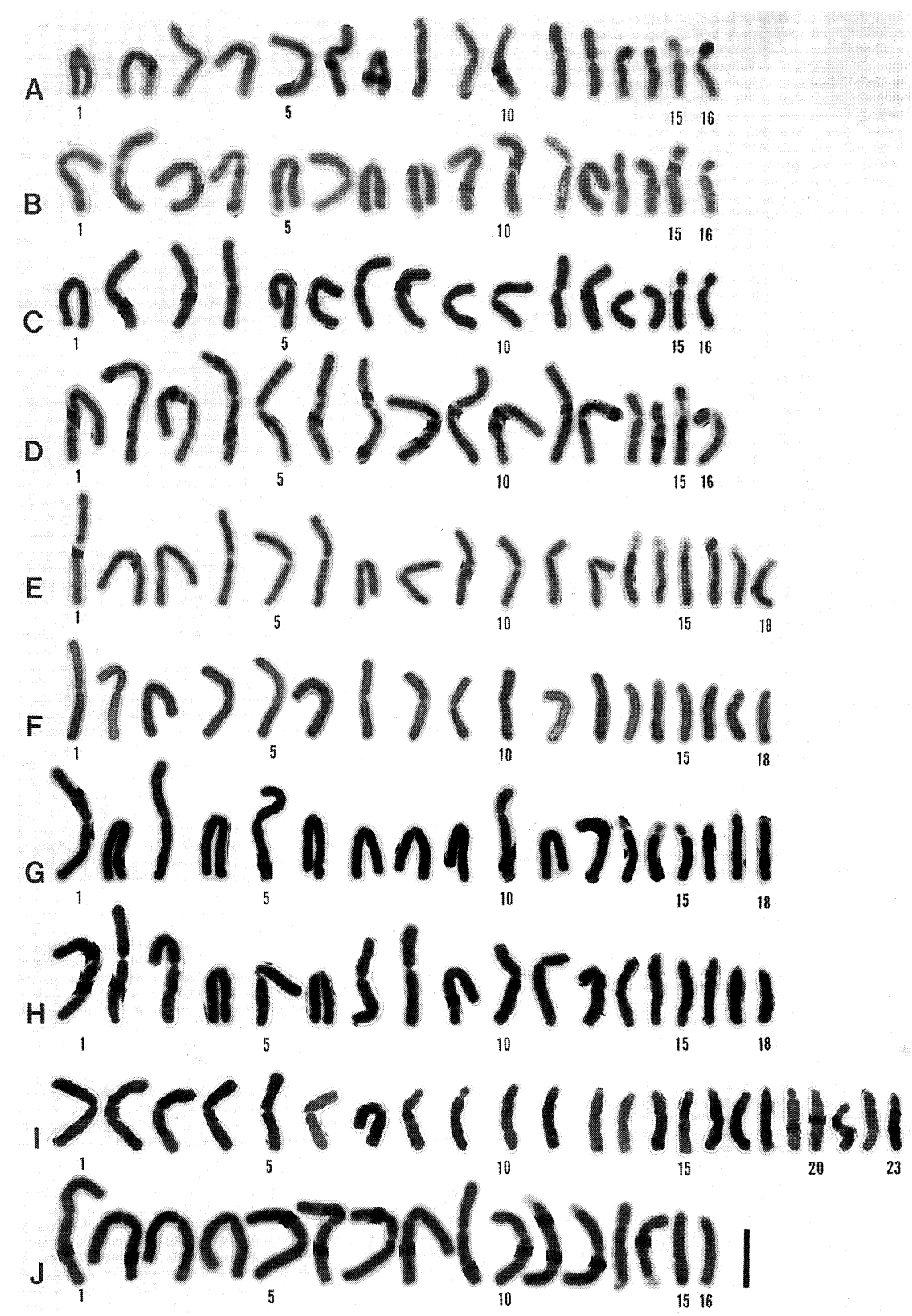

Fig. 1. Karyotypes of 10 species of Zamia and Ceratozamia mexicana. A) Z. angustifolia. B) Z. integrifolia. C) Z. pumila. D) Z. pygmaea. E) Z. furfuracea. F) Z. loddigesii. G) Z. skinneri. H) Z. vazquezii. I) $Z$. muricata. J) Ceratozamia mexicana. $\mathrm{Bar}=10 \mu \mathrm{m}$.

The 4 species of Zamia with the chromosome number of $2 n=16$ showed CMA-positive bands on the proximal region of both short and long arms of the 11th and 12th chromosomes, the proximal region of the short arm of the 13th and 14th chromosomes, and the proximal region of both the short and long arms of the 15th and 16th chromosomes (Figs. 2A, C, E, G, 4A-D). Exceptionally, Z. pumila showed a CMA-positive band on the secondary constriction of the 1st chromosome (Figs. 2E, 4D). On the other hand, the 4 species showed DAPI-positive band, which was weak in brightness and quickly dissapeared, on the centromeric region of 12 chromosomes (Figs. 2B, D, F, H, 

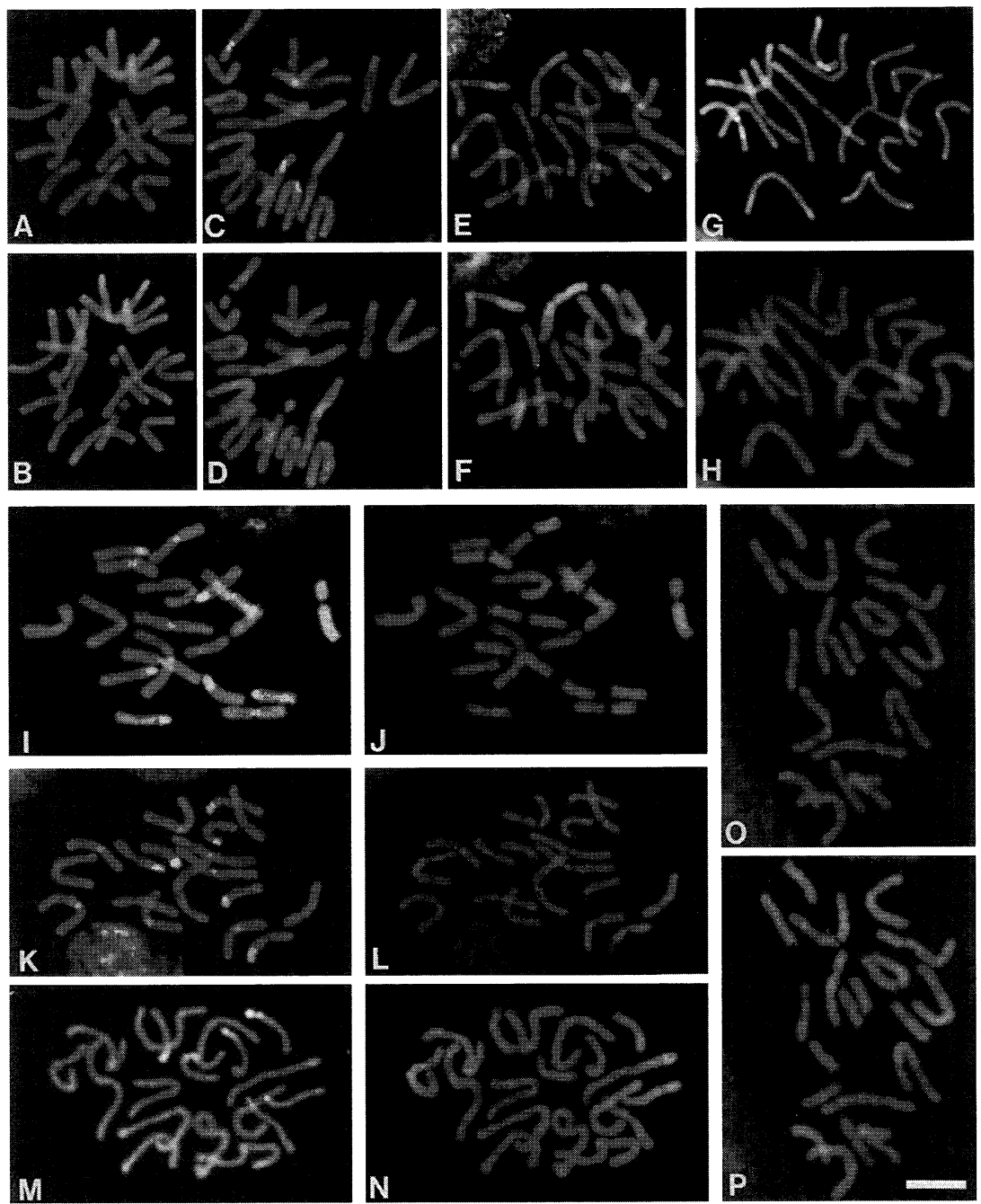

Fig. 2. CMA-DAPI-stained chromosomes of 10 species of Zamia and Ceratozamia mexicana. A, C, E, G, I, K, M and O CMA-stained chromosomes. B, D, F, H, J, L, N, P DAPI-stained chromosomes. A, B) Z. angustifolia. C, D) Z. integrifolia. E, F) Z. pumila. G, H) Z. pygmaea. I, J) Z. furfuracea. K, L) Z. loddigesii. $\mathrm{M}, \mathrm{N})$ Z. skinneri. O, P) Z. vazquezii. CMA-positive bands were corresponded to DAPInegative bands. Bar $=10 \mu \mathrm{m}$.

4A-D). The majority of these chromosomes contained no CMA-positive band. CMA specifically stained guanine (G)- and cytosine (C)-rich regions on chromosome (Schweizer and Nagl 1976), while DAPI specifically stained adenine (A)- and thimine (T)-rich regions (Timmis et al. 1975). The present study in the chromosomes of all of the 9 species of Zamia studied indicated that the CMA-positive regions were corresponded to the strong DAPI-negative region and were considered as high GC-rich regions.

Zamia furfuracea and Z. loddigesii showed CMA-positive bands on the proximal region of both the short and long arms of the 3rd to 10th chromosomes, the whole region of the short arm and the proximal region of the long arm of the 13th to 18th chromosomes (Figs. 2I, K, 4E, F).

Zamia skinneri had CMA-positive bands on the whole region of the short arm and the proximal region of the long arm of the 13th to 16th chromosomes, while were similar to the t-chromosomes of Z. furfuracea and Z. loddigesii. The species also had CMA-positive dots on the consider- 

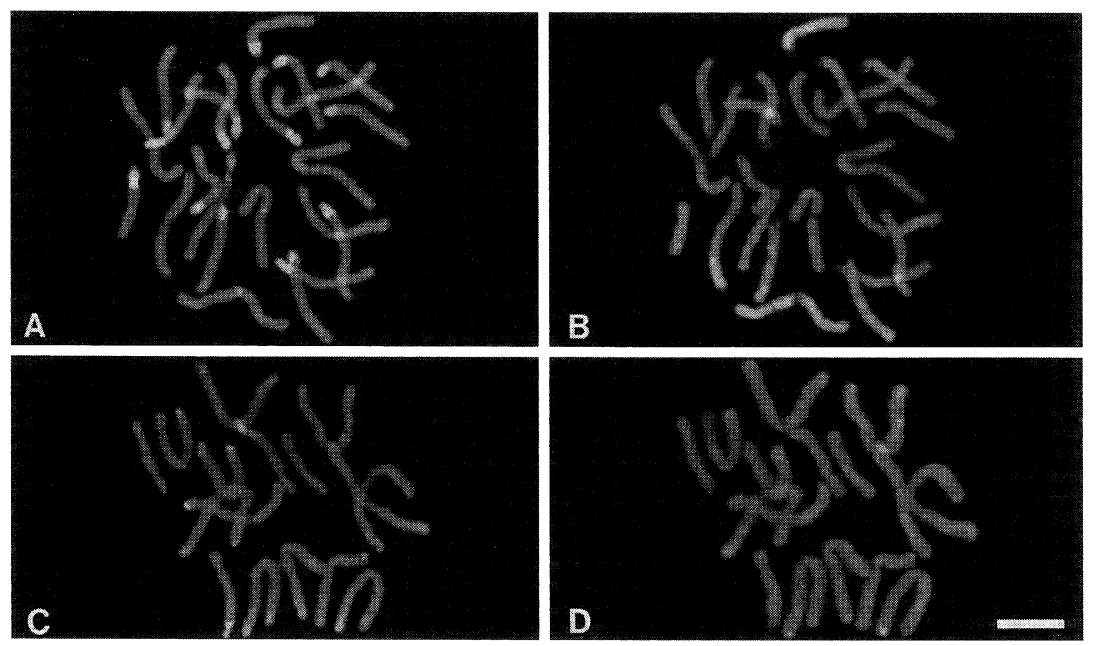

Fig. 3. CMA-DAPI-stained chromosomes of Zamia muricata (A, B) and Ceratozamia mexicana (C, D). A, C) CMA-stained chromosomes. B, D) DAPI-stained chromosomes. Bar $=10 \mu \mathrm{m}$.

able short arm of the 17th and 18th chromosomes (Figs. 2M, 4G).

Zamia vazquezii displayed CMA-positive bands on the proximal region of both the short and long arms of the 3rd to 6th chromosomes and CMA-positive dots on the considerable short arm of the 13th to 18 th chromosomes.

The CMA-positive region appeared on the whole short arm of all of the t- and T-chromosomes in the 4 species with the chromosome number of $2 n=18$. Those regions allowed $t-$ and T-chromosomes to be separated by the characteristics of band-size if the short arm was too small due to the constriction of heterochromatic region to distinguish either $\mathrm{t}$ - or T-chromosome.

The chromosomes of the 4 species with the chromosome number of $2 n=18$ indicated DAPIpositive band on the centromeric region of the chromosomes which had no CMA-positive band (Fig. 2J, L, N, P). These DAPI-positive bands were weak in brightness and quickly disappeared as seen in the chromosomes of $2 n=16$ species.

Zamia muricata exhibited CMA-positive bands on the proximal region of both short and long arms of the 2 nd to 4 th chromosomes and the whole region of the short arm and the proximal region of the long arm of the 8th to 23rd chromosomes (Figs. 3A, 4H). The bands in the 8th to 23th chromosomes were the brightest among the bands of the 9 species of the genus studied. Zamia muricata also showed DAPI-positive dots on the centromeric region of three m-chromosomes and $4 \mathrm{t}$-chromosomes (Fig. 3B) and faint DAPI-positive dots indistinct as seen in the other species of Zamia studied.

Ceratozamia mexicana had CMA-positive bands on the terminal region of the long arm of the 9th and 10th chromosomes, the terminal region of both the short and long arms, the satellite region of the 11 th and 12th chromosomes, and the terminal region of either the long arm or the satelite region of the 13th and 14th chromosomes (Fig. 3C). Sizes of CMA-positive bands in the 9th and 10th chromosomes of the species were clearly different from each other (Fig. 3C). On the other hand, the species has DAPI-positive bands on the centromeric region of all the chromosomes, which were weak in brightness and quickly disappeared (Fig. 3D).

The numbers of CMA-positive regions in the 5 chromosome types found in the species studied were shown in Fig. 4 and Table 2. They suggested that high similarities in number and position of CMA- and DAPI-positive regions were seen among the $2 n=16$ species studied and high variabilities in number and position of CMA- and DAPI-positive regions were seen among the $2 n=18$ species studied. Differences of those numbers and positions were not correlated with differences of 

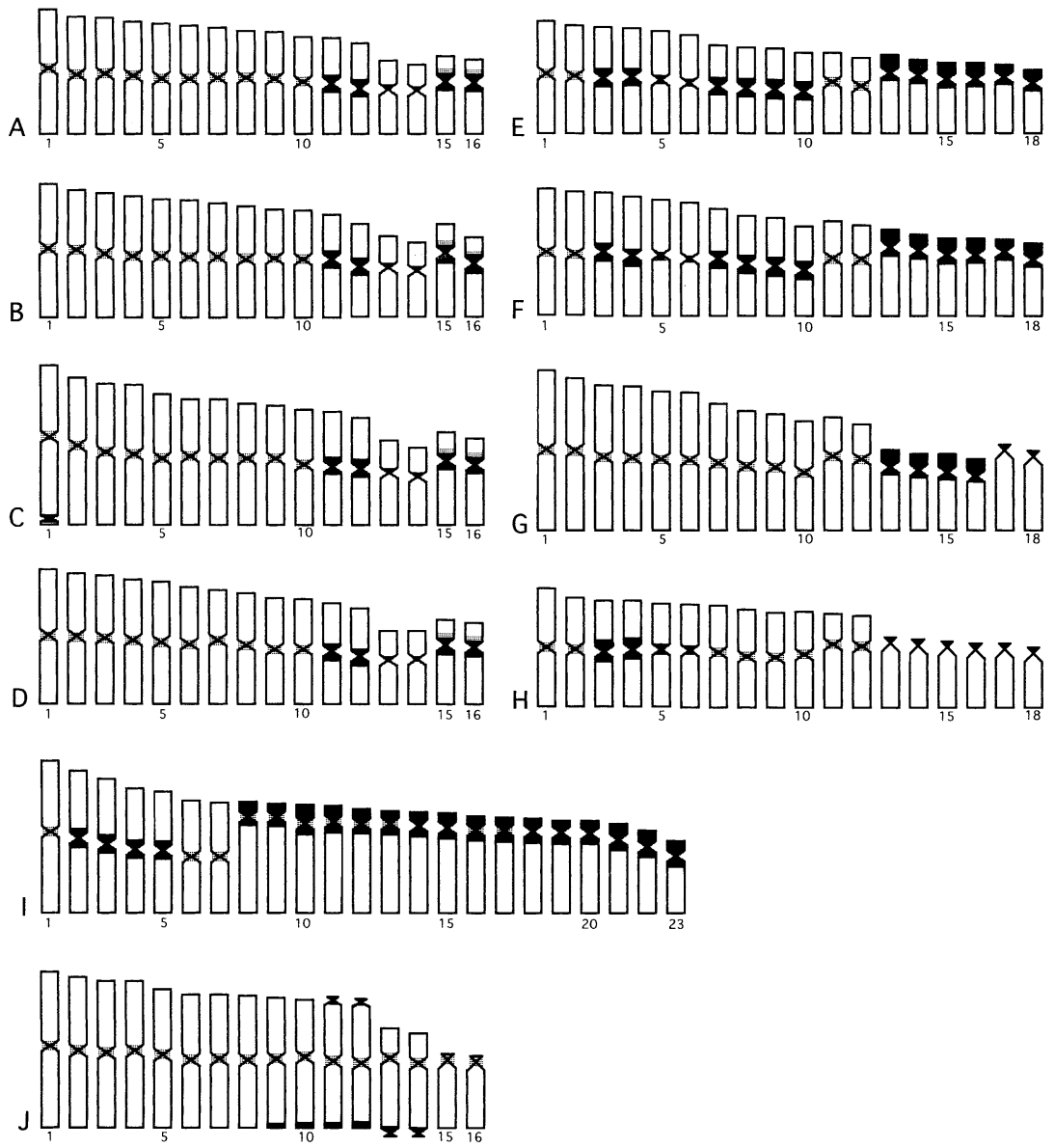

Fig. 4. Ideograms of CMA-DAPI-stained chromosomes in 10 species of Zamia and Ceratozamia mexicana. A) Z. angustifolia. B) Z. integrifolia. C) Z. pumila. D) Z. pygmaea. E) Z. furfuracea. F) Z. loddigesii. G) Z. skinneri. H) Z. vazquezii. I) Z. muricata. J) Ceratozamia mexicana. Black solid areas represent CMA-positive regions and small-dotted areas represent DAPI-positive regions. The Zamia species show the CMA-positive band always on the proximal region of chromosomes, while Ceratozamia mexicana shows CMA-positive bands on the terminal regions of chromosomes. Bar $=10 \mu \mathrm{m}$.

chromosome numbers caused by the simple Robertsonian change an suggested occurrence of the specific structural changes of chromosomes.

The position of CMA-positive regions in Z. muricata with the chromosome number of $2 n=23$ was similar to that in the species with the chromosome number of $2 n=18$, with comparatively various patterns of karyotype components, and position of CMA-positive region: 4 m-chromosomes of Z. muricata as well as the 4 species with $2 n=18$ had the CMA-positive region while only 2 m-chromosomes in the 4 species with $2 n=16$ species had CMA-positive region (Fig. 4). Additionally, the chromosomes of $Z$. muricata showed large CMA-positive regions on the whole short arm of all of the t-chromosomes (Figs. 2I, K, M, 3A).

The karyotypes and the CMA-positive regions in the 9 species of Zamia studied could be correlated to their geographical distribution: The 4 species, characterized with the chromosome number of $2 n=16$ and high similarity in CMA- and DAPI-positive regions of chromosome were mainly distributed in islands of the Caribbean Sea, while the 4 species with the chromosome number of $2 \mathrm{n}=18$ and $Z$. muricata with $2 \mathrm{n}=23$, all varied in karyotype and position and size of CMA- and DAPI-positive regions, were distributed in the continent of Central and South America. Norstog and 
Table 2. Numbers of chromosomes which have CMA-positive region in 9 species of Zamia and Ceratozamia mexicana studied

\begin{tabular}{|c|c|c|c|c|c|c|}
\hline \multirow{2}{*}{ Species } & \multicolumn{6}{|c|}{ Numbers of chromosomes with CMA-positive region/total chromosomes } \\
\hline & $\mathrm{m}$ & $\mathrm{sm}$ & st & $\mathrm{t}$ & $\mathrm{T}$ & sum \\
\hline Zamia angustifolia & $2 / 12$ & $2 / 2$ & $2 / 2$ & - & - & $6 / 16$ \\
\hline Z. integrifolia & $2 / 12$ & $2 / 2$ & $2 / 2$ & - & - & $6 / 16$ \\
\hline Z. pumira & $3 / 12$ & $2 / 2$ & $2 / 2$ & - & - & $7 / 16$ \\
\hline Z. pygmaea & $2 / 12$ & $2 / 2$ & 2.2 & - & - & $6 / 16$ \\
\hline Z. furfuracea & $8 / 10$ & $0 / 2$ & - & $6 / 6$ & - & $14 / 18$ \\
\hline Z. loddigesii & $8 / 10$ & $0 / 2$ & - & $6 / 6$ & - & $14 / 18$ \\
\hline Z. skinneri & $0 / 10$ & $0 / 2$ & - & $4 / 4$ & $2 / 2$ & $6 / 18$ \\
\hline Z. vazquezii & $4 / 10$ & $0 / 2$ & - & - & $6 / 6$ & $10 / 18$ \\
\hline Z. muricata & $4 / 7$ & - & - & $16 / 16$ & - & $20 / 23$ \\
\hline Ceratozamia mexicana & $4 / 12$ & $2 / 2$ & - & - & $2 / 2$ & $8 / 16$ \\
\hline
\end{tabular}

$\mathrm{m}=$ median-centromeric chromosome, $\mathrm{sm}=$ submedian-centromeric chromosome, $\mathrm{st}=$ subterminal-centromeric chromosome, $\mathrm{t}=$ acrocentric chromosome, $\mathrm{T}=$ telocentric chromosome.

Nicholls (1997) morphologically and phytogeographically divided the species of Zamia into 4 groups. They assumed that $Z$. muricata was a member of the Caribbean Basin group since it is distributed in islands of the Caribbean Sea as well as in Eastern South America. Zamia muricata has been reported to have the chromosome number of $2 n=24$ (Norstog 1980) which has been different from $2 n=16$ of the other species of the Caribbean Basin group. Zamia muricata used in this study had the chromosome number of $2 n=23$, differed from $2 n=24$ documented by Norstog (1980), and the position of CMA bands similar to the bands seen in the $2 \mathrm{n}=18$. If $Z$. muricata might be a member of the continent of Central and South America instead of the Caribbean Basin, it would be more simple and easy to explain taxonomic, phytogeographic, and phylogenetic position of the species.

The CMA and DAPI staining methods demonstrated that all of the species of Zamia studied here had CMA-positive regions on the proximal region of certain chromosomes while Ceratozamia mexicana had CMA-positive regions on the terminal region of certain chromosomes. Microcycas calocoma reported by Kokubugata and Kondo (1998) showed the CMA-positive regions positioned in its chromosomes similar to Zamia studied here. Thus, it suggested that Zamia was closely related to Microcycas rather than Ceratozamia with respect to chromosome characteristics. The majority of the species of Zamia studied had symmetrical karyotypes and Microcycas calocoma had an asymmetrical karyotype (Kokubugata and Kondo 1998). This cytological observation supported the morphological and systematical studies of Stevenson (1990).

The 1st chromosome of $Z$. muricata did not have a homologous pair and had no CMA-positive region near the centromere. In contrast, the t-chromosomes, 2 of which might be a homologous match with the first chromosome, contained large CMA-positive region near the centromere. These phenomena may be clarified and justfied if those chromosomes were explained in convenience to be involved and caused with the Robertsonian centric fusion/fission at the CMA-positive region near the centromere.

Further systematic and structural analyses in Zamia as well as the other members of the Zamiaceae should be made to clarify our concepts of species relationships.

\section{References}

Caputo, P., Cozzolino, S., Gaudio, L., Moretti, A. and Stevenson, D. W. 1996. Karyology and phylogeny of some Mesoamerican species of Zamia (Zamiaceae). Amer. J. Bot. 83: 1513-1520.

Hizume, M., Ishida, F. and Kondo, K. 1992. Differential staining and in situ hybridization of nucleolar organizers and cen- 
tromeres in Cycas revoluta chromosomes. Jpn. J. Genet. 67: 381-387.

Johnson, L. A. S. 1963. Cytological and taxonomic notes on Zamiaceae. Contrib. New South Wales Herb. 3: 235-240.

Jones, D. L. 1993. Cycads of the World. Smithsonian Instit. Press, Washington, D. C., p. 312.

Kokubugata, G. and Kondo, K. 1994. Quantitative variability in karyotype of Cycas revoluta. La Kromosomo II-75-76: 2613-2618.

— and - 1996. Differential fluorescent-banding patterns in chromosomes of four species of Cycas (Cycadaceae). Bot. J. Linn. Soc. London 120: 51-55.

- and - 1998. Comparative karyotype analysis of Ceratozamia mexicana and Microcycas calocoma (Zamiaceae) using fluorochrome banding (CMA/DAPI) and fluorescence in situ hybridization of ribosomal DNA. Pl. Syst. Evol. 210: $41-50$.

Levan, A., Fredga, K. and Sandberg, A. A. 1964. Nomenclature for centromeric position on chromosome. Hereditas 52: 201-220.

Marchant, C. J. 1968. Chromosome patterns and nuclear phenomena in the cycad families Stangeriaceae and Zamiaceae. Chromosoma (Berl.) 24: 100-134.

Moretti, A. 1981-82. Quinacrine fluorescence analysis of the chromosomes of Macrozamia Miq. (Cycadales, Zamiaceae). Delpinoa 23-24: 129-136.

- 1990a. Cytotaxonomy of cycads. Mem. New York Bot. Gard. 57: 114-122.

- 1990b. Karyotypic data on North and Central American Zamiaceae (Cycadales) and their phylogenetic implication. Amer. J. Bot. 77: 1016-1029.

—, Caputo, P., Gaudio, L. and Stevenson, D. W. 1991. Intraspecific chromosome variation in Zamia (Zamiaceae, Cycadales). Caryologia 44: 1-10.

— and Sabato, S. 1984. Karyotype evolution by centromeric fission in Zamia (Cycadales). PI. Syst. Evol. 146: $215-223$.

Norstog, K. 1980. Chromosome numbers in Zamia (Cycadales). Caryologia 33: 419-428.

— and Nicholls, T. 1997. The Biology of Cycads. Cornell Univ. Press, Ithaca, p. 363.

Robertson, W. R. B. 1916. Chromosome studies I. Taxonomic relationships shown in the chromosomes of Tettigidae and Acrididae. V-shaped chromosomes and their significance in Acrididae, Locustidae, and Gryllidae. J. Morp. 27: 179-331.

Sax, K. and Beal, J. M. 1934. Chromosomes of the Cycadales. J. Arnold Arb. 15: 255-258.

Schuster, J. 1932. Cycadaceae. In: Engler, A. (ed.). Das Pflanzenreich, 4(1), Engelmann, Leipzing, p. 168 (In German).

Schweizer, D. and Nagl, W. 1976. Heterochromatin diversity in Cymbidium, and its relationship to differential DNA replication. Exp. Cell Res. 98: 411-423.

Stevenson, D. W. 1990. Morphology and systematics of the Cycadales. Mem. New York Bot. Gard. 57: 8-55.

Tanaka, R. and Hizume, M. 1980. C-banding treatment for chromosome of some gymnosperms. Bot. Mag. Tokyo 93: $167-170$.

Timmis, J. N., Deumling, B. and Ingle, J. 1975. Localisation of satellite DNA sequences in nuclei and chromosomes of two plants. Nature 257: 152-155.

Vovides, A. P. 1983. Systematic studies on the Mexican Zamiaceae. I. Chromosome numbers and karyotypes. Amer. J. Bot. 70: 1002-1006.

— and Olivares, M. 1996. Karyotype polymorphism in the cycad Zamia loddigesii (Zamiaceae) of the Yukatan Peninsula, Mexico. Bot. J. Linn. Soc. London 120: 77-83. 